\title{
"Na Calada da Noite": Modernidade e Conservadorismo na Vida Noturna Carioca (1760-1950)
}

\section{"In the Dead of Night": Modernity and Conservatism in the Nightlife of the City of Rio de Janeiro (1760-1950)}

\author{
Marcos Paulo Ferreira de Góis ${ }^{i}$ \\ Universidade Federal Fluminense \\ Angra dos Reis, Brasil
}

Resumo: O objetivo deste artigo é compreender, a partir de um olhar geográfico sobre o passado, o lugar da noite na vida social carioca no período em que a cidade do Rio de Janeiro foi capital do Brasil. O que aqui denominamos vida noturna se relaciona, assim, às práticas ocorridas nos espaços públicos durante a noite. Há poucos relatos sobre esta vida noturna, muito em razão do caráter conservador de parte da elite carioca, a qual parece ter preferido realizar atividades noturnas em ambientes privados. Os dados disponíveis nos informam, entretanto, que o processo de ocupação dos espaços públicos durante a noite se desenvolveu a partir de práticas populares em algumas áreas da cidade, especialmente na proximidade do seu centro, até meados do século XX. O avanço da noite como momento de publicidade parece ter assim correlação com mudanças mais gerais na organização da cidade e seu processo de modernização.

Palavras-chave: Vida Noturna; Sociabilidade; Iluminação; Espaços Públicos; Rio de Janeiro.

\begin{abstract}
The purpose of this article is to understand, from a geographic look at the past, the place of night in the social life of Rio de Janeiro in the period in which the city was the capital of Brazil. What we call here nightlife relates thus to the practices occurring in public spaces at night. There are few reports about this nightlife, much because of the conservative character of the carioca elite, which seems to have preferred to conduct evening activities in private places. The available data tell us, however, that the process of public space appropriation during nightime was developed from popular practices in some areas of the city, especially near its center, until the mid-twentieth century. The progress of the night as a time of publicity seems to correlate well with more general changes in the organization of the city and its modernization process.
\end{abstract}

Keywords: Nightlife; Sociability; Urban Lighting; Public Space; Rio de Janeiro.

\footnotetext{
' Professor Adjunto do Departamento de Geografia e Políticas Públicas - IEAR/UFF. marcosruler@ gmail.com.
} 


\section{Introdução}

Em um livro sobre a história da cidade do Rio de Janeiro, o capítulo sobre a vida noturna ainda permanece incompleto. Já houve algumas tentativas de escrevê-lo, mas os parágrafos dedicados à vida pública noturna precisam de maior refinamento e precisão. Esta tarefa não parece ser simples, visto que há poucas memórias da noite do passado, muitas vezes apenas fragmentos das práticas cotidianas da população carioca de então, vinculados aos meios discursivos oficiais da imprensa, do Estado e do núcleo empresarial. Boa parte desta história possui restrições em relação às classes sociais, raças e gêneros daqueles que estavam nos espaços públicos durante a noite. Neste sentido, as fontes oficiais oferecem uma fotografia parcial do passado da área central da cidade, ou seja, se limitam às atividades da elite da capital e suas atividades noturnas, o que ainda é uma restrição deste artigo. De forma geral, o que aconteceu na calada da noite permanece ainda pouco conhecido.

Apesar dos limites expostos, o interesse fundamental contido neste artigo é apresentar uma visão geográfica sobre a noite na área central da cidade do Rio de Janeiro do passado. Acredita-se que há um relativo desconhecimento sobre as formas de se viver nos espaços públicos da cidade durante este período, especialmente nos séculos XVIII e XIX. Esse hiato não será, no entanto, compensado plenamente nesse breve artigo pelas razões colocadas acima. Pretende-se, no entanto, contribuir para um debate mais geral sobre o tema, inserindo-o no processo de evolução urbana do Rio de Janeiro. Esse contexto dará fundamento ao problema da existência da vida noturna em relação aos avanços adquiridos com a inserção de "modernidades" no espaço urbano: sistemas de distribuição de energia e de iluminação pública, melhoria das formas de mobilidade urbana, criação de técnicas de entretenimento, atividades de lazer em espaços públicos, regulações da ordem urbana e segurança pública etc.

O maior desafio será, portanto, compreender a mudança histórica da noite como um fenômeno geográfico (NORTON, 1984; MELBIN, 1987), tendo como parâmetros as fontes disponíveis sobre a espacialidade da vida noturna na área central do Rio de Janeiro. Podemos resumir este caminho segundo alguns períodos arbitrariamente definidos e que nos indicam transformações nas formas de se viver a noite do Rio. Um primeiro momento pode ser estabelecido em meados do século XVIII com a adoção de novas medidas de prevenção de incidentes através da criação de pontos de luminosidade na cidade coIonial, ainda marcada pela aparentemente calma vida social noturna (DUNLOP, 2008). Um segundo momento pode ser seccionado pelo advento do pensamento moderno, motivado pela incorporação de novas tecnologias e formas de sociabilidade adquiridas a partir do exemplo europeu. Um terceiro período engloba aquilo que ficou conhecido como sendo a "era de ouro da noite carioca", quando a cidade foi intitulada como "a cidade luz dos trópicos" e se transformou em referência cultural para a república brasileira.

A periodização não deverá ser vista aqui como uma rígida categorização das práticas sociais noturnas, mas, de outro modo, como uma maneira de observar e de organizar as transformações das relações entre cidadãos e espaços públicos durante o período noturno a partir de uma estruturação diacrônica da sua história. De forma antecipada pode se afirmar que em cada período houve ajustes entre os elementos físicos e técnicos, os 
comportamentos e as práticas sociais e os significados atribuídos à noite. Dentro desta perspectiva que reúne essas três grandes dimensões de análise procurou-se construir um modelo de análise discursiva das fontes oficiais históricas. Em boa parte do texto será feita referência a textos que de alguma forma trataram das práticas sociais no período noturno. Na medida do possível, outras fontes serão apresentadas, como artigos de jornais e revistas, e referências a fatos do passado serão discutidas a partir de outras pesquisas acadêmicas. Por se tratarem de fontes que tiveram que lidar com dados oficiais, o quadro rascunhado se limita às práticas que tiveram maior visibilidade naquele momento da sociedade carioca. Apesar de este fato obscurecer determinadas práticas, ele nos oferece também um recorte moral da sociedade, expondo os seus valores dominantes em cada período. Acredita-se que um esboço da noite do passado da cidade do Rio de Janeiro poderá ser estabelecido, especialmente no que se refere aos lugares de manifestação da vida social na área central da urbe carioca.

\section{Noites, Modernidade e Conservadorismo}

Somos cotidianamente confrontados com a presença da noite, a qual não deixa de orientar as nossas práticas. Ainda que atualmente tenhamos novas formas de lidar com os ciclos naturais, o imaginário humano continua criando relatos sobre as experiências vividas e as apresentando em formas variadas para os leitores. Uma das fontes fundamentais para entender o papel da noite no passado de uma cidade é o jornal, popular desde a metade do século XIX no Rio de Janeiro. Esta fonte narra a aventura de estar nas cidades e, como a crônica, nos oferece uma janela para os acontecimentos passados em páginas de classificados, de relatos policiais, de ofertas de lazer, de folhetins etc.

Nos jornais surgem muitas imagens sobre a noite, aparecendo sempre ambígua, parcialmente descoberta, parcialmente misteriosa, exibida em um diferenciado jogo de visibilidade. A partir dos argumentos contidos nas obras de autores como Bureau (1997), poderíamos notar que a dicotomia entre luz e escuridão é bem importante para a modernidade, associando lugares a sensações e incentivando ações que buscariam "desvelar os segredos da noite". Esta ordem relativa ao imaginário sobre noite e dia pode também ser compreendida em termos de sua espacialidade, especialmente se nas fontes abordadas houver alguma indicação de lugares e de comportamentos a eles associados, se se estabelecer uma geografia de tais atividades.

De alguma maneira, ainda hoje se reproduz o medo da escuridão e as possibilidades de encontros indesejados, normalmente associados a comportamentos transgressores. Quando se diz que a noite é um momento que habilita a manifestação de um comportamento transgressor é porque se torna evidente a sua comparação com o comportamento diurno (WILLIAMS, 2008). Tornou-se comum dizer que a noite é transformada em período de ruptura, das tentações dionisíacas em contraste com a austeridade apolínea. O dia é o momento do trabalho e da manutenção da ordem; a noite é o momento da transgressão da ordem e da adoração ao prazer. Se este caminho for correto, então veremos que nas páginas policiais e nos relatos de ocorrências a noite aparece também em muitos momentos, indicando os lugares perigosos da cidade. Da mesma forma que as embrionárias notícias da sociedade carioca poderão nos mostrar o lado lúdico e festivo da 
noite. Há nas páginas dos principais jornais do período imperial referências aos roubos, às fugas de escravos e às ações imorais nas ruas da área portuária da cidade. Ao mesmo tempo, as notícias de festas de mascarados, de óperas e de "dansas" são bem comuns.

A presença de notícias sobre ações ilegais costuma vir acompanhada de atos de regulação das práticas. Diversas ações tentaram regular as atividades noturnas e limitar o uso do espaço público durante a noite, contudo, essas ações, ao mesmo tempo, forneceram condições e limites aos usos sociais a certas áreas da cidade, reforçando as marcas de uma geografia da noite. O processo de ocupação dos espaços públicos permaneceu sendo uma questão política essencial para a administração urbana, especialmente nas áreas próximas aos centros de governo e nas áreas que concentravam atividades nobres, como, por exemplo, os teatros, os restaurantes e os cafés (BALDWIN, 2012). Naqueles lugares de grande visibilidade e furor social, mantinham-se as luzes acesas e buscava-se conter os comportamentos indesejados como, por exemplo, a mendicância, a bebedeira e o protesto (PALMER, 2000). A contenção dos "usos sujos" é, aliás, uma muito antiga prática na cidade do Rio de Janeiro (MATTOS, 1991).

Aquilo que Murray Melbin (1978) denomina de "conquista da noite urbana" é um processo que incorpora fundamentalmente uma substituição de práticas tidas como ilegais, imorais e insignificantes por práticas nobres, permanentes e modernas. A ideia inicial parecia ser transformar a noite em dia, como se a civilidade da vida diurna pudesse ser transportada para as fronteiras da noite. Este processo não se daria somente a partir de uma insistente perseguição às práticas transgressoras, mas também, de forma complementar, a partir de mudanças na própria forma da cidade. Desse modo, a modernidade - como modo de ser e como modo de intervir no mundo - seria um dos meios de manifestação dos valores conservadores da sociedade carioca de então.

\section{As Primeiras Luzes, o Cerimonial Religioso e o Policiamento das Ruas}

Passados mais de dois séculos de sua fundação, a cidade do Rio de Janeiro parecia se manter como uma acanhada aglomeração de casas entremeadas por apertados arruamentos mal iluminados durante a noite por candeeiros e velas sobre oratórios religiosos (DUNLOP, 2008). O que ocorria na noite da cidade é ainda pouco conhecido e mais fontes precisam ser exploradas para descobrirmos esta parte da história do Rio, já que os relatos que tivemos acesso começam nos anos de 1830. O que se suspeita é que significativa parte desta "vida noturna" tinha o seu lugar em ambientes privados, como estalagens, bordéis, teatros, igrejas e tavernas. Sobre os espaços públicos da cidade não há quase referências sobre o uso noturno, em geral mantendo-se as referências em relação ao cerimonial religioso (MENDONÇA, 2004).

Os limitados recursos da capital da colônia não devem ter permitido também maiores investimentos nos espaços públicos da cidade, visto que, mesmo após a elevação do Rio de Janeiro à capital, havia uma reduzida capacidade de se gerar tais recursos, o que se deveu, em grande medida, à crise da extração do ouro nas Minas Gerais. O período entre 1750 e 1790 pode ser caracterizado como de estagnação econômica e urbana (PESAVENTO, 2012). O contexto global de estagnação nos ajuda a compreender as limitadas ações dos governantes na produção de espaços para a sociedade carioca. 
A primeira ação de produção de um espaço para a realização de atividades públicas se deu com a criação do Passeio Público, em 1783, e por razões de higienização urbana, com o aterro da Lagoa do Boqueirão da Ajuda (SEGAWA, 1996). A ideia de lazeres em espaços públicos não parece fazer parte ainda da cultura do carioca até então, ainda menos durante a noite, na qual as ruas pareciam pouco povoadas (FERREIRA, 2009). Como exceção, a própria rua que dava acesso ao Passeio Público, a Rua das Belas Noites (atual das Marrecas), na qual as pensões francesas recebiam clientes para atividades privadas (MITIDIERI, 2008).

Como centro do poder colonial português nas Américas, o Rio se tornou um laboratório para as experiências urbanas e o local de demonstração do poder e da riqueza da metrópole portuguesa. A centralidade que o Rio de Janeiro adquire a partir de então tende a se desdobrar em um conjunto de medidas que desenvolvem a urbanidade da sociedade carioca da época. Um dos sintomas da centralidade da cidade do Rio de Janeiro pode ser descrito pelo papel que esta adquire enquanto centro da formação da cultura nacional, porta de entrada do comércio internacional e espaço para o florescimento de uma vanguarda política brasileira (LESSA, 2005). A antiga Praça do Carmo (atual Praça $\mathrm{XV}$ de Novembro) se tornou o centro de tais atividades mercantis, políticas, religiosas e culturais, sendo, portanto, outro polo de atração da população durante o dia e uma das primeiras áreas a ter dispositivos de segurança e de vigilância, com soldados e velas dispostas nas áreas externas dos prédios públicos (MENDONÇA, 2004). A questão da vigilância parecia ser bem importante, mas há poucas referências aos imaginários sobre a noite de então que confirmem tal afirmação, somente relatos da busca de proteção dos casos de roubos e de prostituição na área do Cais do Valongo.

A primeira ação pública de iluminação das ruas da urbe carioca foi realizada somente no final do século XVIII pelo então Vice-Rei Conde de Resende, a qual era composta de pouco mais de cem lampiões com candeeiros de azeite de peixe (DUNLOP, 2008), localizados entre a Rua Direita (atual 1ํ de Março) e o Campo de Santana (FERREIRA, 2009). As luzes estabeleciam, ainda na década de 1790, os limites da cidade, o que se ampliou com a chegada da Corte em 1808, chegando ao número de quinhentos lampiões até 1820 (LESSA, 2005).

Durante algum tempo a obrigação de instalação e fiscalização das condições da iluminação pública esteve a cargo da polícia colonial, o que aponta que a iluminação em sua origem foi financiada por questão de segurança, como também foram os casos de grandes cidades europeias como Paris e Londres alguns anos antes (SCHIVELBUSCH, 1987). A ação de iluminar as ruas da cidade esteve, assim, associada ao problema da ordem urbana, o que pode ser o indicador preliminar de uma incipiente vida noturna ou, pelo menos, da presença de mais pessoas nas ruas durante a noite. Uma das preocupações fundamentais até pelo menos metade do século XIX era a fuga de escravos, normalmente ocorrida durante a noite, como relatado em diversas edições do Jornal do Commercio a partir de 1827.

O quadro cultural no Rio de Janeiro até 1808 apresentava, portanto, uma vida noturna aparentemente modesta, com poucas atividades ocorrendo nas ruas, praças e parques da cidade, mas com maiores referências a práticas ocorridas em pequenos teatros, acanhados restaurantes e simples pensões (FEIJÓ e WAGNER, 2014). Pouco 
parece ter sido promovido na época, apenas alguns teatros, como o Teatro do Padre Ventura e o Theatro de São Pedro de Alcântara, e as academias de leitura e de ciência, que conseguiam congregar algumas pessoas (LESSA, 2005). Algumas bandas e músicos portugueses fizeram algum sucesso tocando o lundu e a modinha em salões e casas do Rio. Além disso, a proibição de tavernas no centro do Rio (desde 1670), a repressão violenta à vadiagem e o toque de recolher durante a noite mantinham um cenário bem próximo daquele descrito por Mumford (1998) para as cidades medievais europeias em pleno fim do século XVIII.

Sem dúvida a chegada da corte portuguesa produziu efeitos duradouros na vida urbana do Rio. Em primeiro lugar, uma onda de crescimento demográfico, tendo aproximadamente quinze mil membros da corte encontrado uma cidade com uma população estimada em cerca de cinquenta mil, concentrados no que hoje é a área central da cidade (CAVALCANTI, 2004). Em segundo lugar, a vinda da burocracia portuguesa ao Brasil promoveu um crescimento das funções e um rearranjo das hierarquias sociais no Rio de Janeiro. Por fim, economia e cultura foram afetadas pela complexificação do sistema de trocas, sendo influenciadas pelas nações aliadas à corte portuguesa, o que deve ter tido consequências para a vida noturna, especialmente na área portuária.

Após a chegada da Corte Portuguesa, mecanismos de ordenamento urbano foram criados e ajudaram a ampliar a vida social na cidade. A iluminação passou a ser custeada pela coroa portuguesa, seja para os cerimoniais, seja para a segurança pública, incumbida a Intendência Geral da Corte, responsável, ao mesmo tempo, pela segurança e pelas obras na cidade (MENDONÇA, 2004). Assim como a obrigação de instalar mecanismos de iluminação para as noites, a Intendência construiu ruas e largos na cidade, bem como espaços cênicos como o Teatro São João, tornando-se um dos meios pelos quais a vida urbana se pronunciava (DUNLOP, 2008). A entrada da modernidade foi conduzida a partir de um projeto que previa melhorar as condições de habitabilidade e ampliar a vida urbana nos espaços públicos da cidade. De início, a ideia de ordenamento parecia ter um forte vínculo com as mudanças no espaço físico do Rio, mas aos poucos foi se tornando um modo de conter os comportamentos indesejados (brigas, roubos, prostituição, mendicância etc.) por meio de leis e de reformas que visavam esconder os dilemas da cidade e abrir a cidade para uma forma de lazer comum às cortes europeias.

O incentivo ao ensino da alta cultura, a apresentação de música erudita, a importação da moda parisiense e a promoção de peças, recitais e óperas aos poucos abriam a noite como tempo para o lazer da corte (FEIJÓ e WAGNER, 2014). Ao mesmo tempo, as manifestações de origem africana eram parcialmente absorvidas e mescladas na música, como no caso do lundu. Outras manifestações populares eram silenciadas, como a capoeira e o jongo, as quais poderiam ser contidas pelo aparato policial, caso fossem demonstradas publicamente. Neste período inicia-se a gestação da cidade como uma capital com diversas influências culturais que se materializavam no modo de vida local. A visibilidade das práticas foi, no entanto, seletiva, dando maior centralidade às práticas sociais da elite e obscurecendo algumas manifestações que ocorriam na calada da noite, longe do foco das chamas das velas da Intendência Geral da Corte. 
"Na Calada da Noite": Modernidade e Conservadorismo na Vida Noturna Carioca (1760-1950)

\section{A Iluminação a Gás, o Bonde e o Teatro}

O marco inicial deste período pode ser delimitado a partir do retorno da corte a Portugal, o início do Brasil Imperial, cuja capital, o Rio de Janeiro, se estabelece enquanto Município Neutro e adquire os contornos territoriais atuais. A partir de 1840 há um elevado crescimento demográfico, dos pouco mais de cinquenta mil habitantes no início do século XIX chega-se a mais de quinhentos mil habitantes em 1890, sendo cerca de 20\% de imigrantes estrangeiros (LESSA, 2005). Este momento também é marcado pelas primeiras iniciativas de modernização do país e pela preeminência do Rio de Janeiro como capital cultural nacional. As iniciativas de utilização do gás de hulha são criadas no Rio, assim como o surgimento de linhas de bonde e de redes ferroviárias. Com isso começa a operar uma mudança no hábito do carioca e novas formas de sociabilidade durante a noite passam a ser relatadas pela imprensa oficial. Peças teatrais e óperas são anunciadas durante a noite no Theatro de São Pedro de Alcântara, números de dança e serviços culinários aparecem na Rua do Ouvidor, a venda de pratos especiais nas noites de sábado e sorvetes na Rua do Sabão também se tornam anúncios comuns (Jornal do Commercio, 1827, em várias edições).

Com a independência nacional, o Rio de Janeiro se transforma em capital do Império, passando a ser a referência do Estado brasileiro, tanto em termos culturais quanto no que diz respeito ao progresso econômico. A segunda metade do século XIX é, portanto, um período de grandes mudanças, uma fase de transição para a modernidade. Esta transição inclui o avanço na assimilação de novas tecnologias, a entrada do capital internacional, o surgimento de uma maior diversificação do consumo e a abertura do processo de industrialização (ABREU, 2006). A cidade passou também por um acelerado processo de fragmentação social e espacial que viria a caracterizar a urbe carioca nas décadas seguintes (MOURA, 1995).

Os experimentos urbanos na formação da metrópole moderna se constituíram em investimentos técnicos sobre o território, em busca de novas terras e de novas possibilidades de diversificação do investimento nas áreas urbanas. No caso específico da iluminação pública, as inovações repercutiam esse modelo, evidenciando o crescimento das atividades noturnas e buscando, ao mesmo tempo, promover novas práticas. A primeira iniciativa bem-sucedida foi feita pelo Barão de Mauá, membro da nova burguesia (com títulos nobilitários) formada no início do século XIX, e um dos primeiros empreendedores da indústria brasileira no período posterior à crise da mineração. A construção do gasômetro e a instalação dos encanamentos de gás em 1853 previam não só iluminar as ruas da cidade, mas oferecer o serviço para o comércio, as indústrias e as residências da área central da cidade. Com isso, não só as atividades públicas, mas também as privadas poderiam ocorrer por mais tempo durante o período noturno. Esta iniciativa replicava os modelos propostos anos antes para cidades europeias e norte-americanas, sendo o Rio a primeira cidade a adotá-la no país (FERREIRA, 2009).

Ante-hontem, anniversario do juramento da constituição do império, vio a cidade de S. Sebastião do Rio de Janeiro a introducção de um grande melhoramento. Os lampeões do fétido azeite de peixe, donde partia lúgubre clarão, 
começarão a ser substituídos pelo gaz que inundará suas ruas e praças com um oceano de luz.

Era tempo de imitarmos as cidades da Europa e da América que nos precedêrão na carreira da civilisação. O que diria o estrangeiro que aportasse às nossas praias vendo o que a rainha da América Meridional apresentava durante as noites o triste espectaculo de uma necropolis? Quando o astro da solidão não allumiava a abobada celeste, poucas eram as famílias que, sem um fim immediato, deixassem suas casas para passeiar pelas ruas escuras, immundas e mal calçadas desta opulenta cidade. (Jornal do Commercio, 1854, edição n. 85, p. 2).

Admite-se que com a instalação dos bicos de gás nos logradouros públicos tenha ocorrido uma evolução na vida noturna da cidade em relação ao período colonial. Até então só a parte central da cidade, onde se localizavam os prédios administrativos da corte, mostravam alguma vida noturna. Os primeiros cafés, restaurantes e teatros começaram a funcionar para além da hora usual de passeios, o que se seguiu de um crescente movimento nas ruas à noite, garantido também pela disponibilidade dos serviços de bondes (DUNLOP, 2008). Isto permitiu não somente a segurança para a circulação nas ruas da cidade, mas também que a vida social se estendesse durante as horas da noite em que usualmente se preferia o recolhimento para os afazeres domiciliares, o que nesse caso parece ter fortes relações também com a proliferação dos teatros na cidade.

Além do desenvolvimento da iluminação a gás, a melhoria e a expansão dos sistemas de transportes foram cruciais para a criação de atrações no centro da cidade, em especial atividades criadas para o uso noturno. A partir de 1858 as estradas de ferro ocupariam um papel importante na ampliação da área urbana para a Zona Norte da cidade. A partir de 1868 os bondes teriam o mesmo papel para a ocupação da Zona Sul (ABREU, 2006). A associação com os bondes permitiu também que a elite carioca pudesse gozar de maior proximidade com os equipamentos culturais de então. As linhas de bonde ligavam os bairros do Centro, da Zona Sul e da Tijuca aos principais teatros e restaurantes da cidade, os quais se localizavam no entorno do Largo do Rocio (atual Praça Tiradentes), principalmente após a expulsão de parte da população pobre e a urbanização da área a partir de 1846 (MOURA, 1995).

A ligação da cidade pelos bondes promoveu, aos poucos, uma concentração de lazeres no Largo do Rocio, dentre os quais casas de dança, salões, clubes e teatros. A partir de 1870 a área passou a ser o centro da vida noturna carioca, deslocada dos antigos teatros nas cercanias da Rua do Ouvidor (FEIJÓ e WAGNER, 2014). Alguns teatros foram inaugurados ao longo daquele período, sendo o Teatro São João o principal, construído em 1813, e que recebeu as principais obras de João Caetano (LESSA, 2005). O Teatro São João costumava ser o palco das principais atrações internacionais trazidas pela corte, apresentando peças, óperas e espetáculos que buscavam exibir a cultura europeia no Brasil, um lugar para o desfile da société carioca (LIMA, 2000). Após o São João surgiram ainda outros como o Teatro Apollo, na Rua do Lavradio; o Alcazar Fluminense, na Rua Teotônio Regadas; e o Theatre Franc-Brésiliene, atual Carlos Gomes, em frente à Praça Tiradentes. Esses teatros criaram um lugar no imaginário carioca ligado 
às artes, permanecendo o antigo Rocio como centro da vida social noturna de parte da elite e da pequena classe média carioca até meados do século XX. Nos teatros menores eram encenadas peças circenses, trechos de peças famosas, sátiras e variedades, atrações muito similares ao vaudeville americano da mesma época (NASAW, 1993). Durante o Segundo Reinado ficou muito popular o teatro musicado e o café cantante, os quais eram muito mais informais e aceitavam um público mais modesto e menos abastado que não possuía capital e nem a vestimenta necessária para frequentar os grandes teatros da Praça Tiradentes (LIMA, 2000). Imagina-se que a frequência a essas casas mobilizava também um significativo número de pessoas na praça e nas ruas do entorno.

A importância dos teatros na vida social carioca do fim do século XIX está ligada ao surgimento de outras atividades correlatas. Os cafés seguiram o modelo francês, sendo provavelmente criados pelos imigrantes que chegaram ao Rio após 1814 - o que também poderia ser dito para as estalagens e pensões francesas (LESSA, 2005). A combinação de tais atividades deve ter promovido a ocupação de espaços públicos da urbe carioca, especialmente nos horários de entrada e de saída dos espetáculos. As atividades privadas nos espaços de entretenimento eram combinadas com festividades públicas em alguns momentos. Ainda em 1840 os primeiros bailes de carnaval foram organizados em clubes e teatros, "transbordando" para as ruas da cidade, as quais foram decoradas com elementos do cerimonial português adaptados aos motivos franceses e africanos (FEIJÓ e WAGNER, 2014). Na edição 41 de 1840 do Jornal do Commercio há diversos anúncios dos bailes mascarados, adaptados das festas europeias, os quais ocorriam durante a noite e só terminavam nas últimas horas da madrugada:

[No Campo da Aclimação] os bailes de carnaval nos dias já designados principiarão sempre às 9 horas e terminarão às 4 da manhã [...]. [No Theatro de São Pedro de Alcântara] as portas do Theatro serão abertas às oito horas, e o baile principiará às 9 horas e acabará às 3 da manhã [...]. (Jornal do Commercio, 1850, edição n. 41)

Até o final do século XIX, cordões e ranchos, como o Cordão Aliança e o Invencíveis do Catumby, eram as formas populares de ocupação dos espaços públicos do centro da cidade, inaugurando a tradição que depois seria traduzida nos blocos carnavalescos (GONÇALVES, 2007). Os bailes poderiam percorrer a madrugada e tomar as ruas da cidade, mas a ordem social era mantida por um rígido aparato policial. Ainda assim a cultura do povo era assimilada e mesclada aos modismos europeus. O caso do maxixe, que ficou muito popular no final do século XIX (LESSA, 2005), pode ser um exemplo dessa mistura do popular com o estrangeiro. O samba é ainda outro exemplo de um período de experimentações que tiveram importante influência na vida noturna carioca, seja através da ampliação dos meios técnicos, seja pela transformação do modo de vida urbano carioca no fim do século XIX (MOURA, 1995). Nesse período as atividades de lazer em espaços privados começavam a se insinuar sobre os espaços públicos, abrindo o caminho para a boemia carioca consagrada no bairro da Lapa, mas fragmentada em tantas casas de espetáculos, círculos de dança e inferninhos em outras áreas do centro da cidade. 


\section{A Eletricidade, a Boemia e a Reforma Urbana}

A era de ouro da boemia pode ser também vista como a era da eletricidade e da abertura da cidade colonial. Naquele período a iluminação urbana acompanhou os avanços mais gerais dos sistemas de transportes, do saneamento, do calçamento e de demolições em toda área central da urbe carioca. As atividades de entretenimento também foram beneficiadas com a adoção de nova iluminação em teatros, o uso de cinematógrafos em teatros de variedades como, por exemplo, O Moulin Rouge na Praça Tiradentes e até mesmo máquinas de música que acompanhavam crooners em cafés cantantes no centro da cidade (LIMA, 2000). Assim como a iluminação, os equipamentos de entretenimento foram rapidamente incorporados à vida social carioca, recriando os cenários noturnos de algumas partes da cidade e reproduzindo os modelos aristocráticos da Europa.

Ao mesmo tempo em que se consolidava a reforma urbana, mantinha a cidade alguns pontos obscuros, marcados pela segmentação social da época, estigmatizados pela presença dos antigos escravos, dos imigrantes e dos migrantes de toda a parte. Esta cidade que agora passava também a recobrir as áreas dos antigos engenhos, para além da área do mangue e nas encostas dos maciços costeiros, parecia ter outro ritmo, com outras vidas noturnas ainda desconhecidas. Nas bordas da área central, nas áreas alagadiças da Saúde, da Gamboa e da Praça Onze outros costumes pareciam acender os habitantes. Em terrenos e em fundos de casas surgiam rodas de samba, de choro, umbigadas, e toda sorte de dança da qual somente temos lembrança pelos resquícios da história oral (MOURA, 1995). No centro da cidade, as barracas de aguardente, as mesas de jogos baratos e as luzes dos cabarés pululavam de gente pelos cantos da Lapa e da Glória.

A Reforma de Pereira Passos conduziu algumas transformações no uso dos espaços públicos da área central, sem dúvida, deslocando centralidades noturnas e reorganizando a geografia das atividades de entretenimento. A área ao longo da Avenida Rio Branco se tornou centro do lazer e das belas artes, articulando cafés, teatros e cinemas em um cenário noturno iluminado pelas lâmpadas incandescentes. Ao mesmo tempo, com a Reforma, lugares de sociabilidade e de boemia foram lentamente sendo desalojados, como os quiosques na área central, que abasteciam os trabalhadores da cidade com bebidas baratas. Bêbados, vadios e ociosos foram aos poucos deslocados para as "bandas" da Lapa, em meios aos bares, prostíbulos e cabarés (MATTOS, 1991).

A vida noturna nos espaços públicos aparece nos jornais de duas formas: a primeira delas é caracterizada pelo lazer "médio", dos funcionários públicos, dos pequenos empresários urbanos, da elite rural que vivia na capital, dos visitantes da cidade e dos comerciários. Ela se concentrava fundamentalmente nos teatros, cinemas, cafés, clubes e restaurantes da Praça Tiradentes (em decadência) e do entorno da Praça Floriano (Cinelândia). Era o que se dizia ser o "lazer familiar" (MATTOS, 2011), muito comum em casas como o Alcazar Fluminense:

Abertura desta attrahente casa de espectaculos, depois dos grandes melhoramentos, que offerecem ao publico todas as regalias e confortos, para bem passar as noites calmosas, apreciando uma $1^{\text {a }}$ companhia neste gênero [...] Grande 
companhia de Comedia, Opereta, Vaudeville, Cançoneta e Baile. Uornal do Brasil, 24 de janeiro de 1901, p. 6)

A outra vida noturna acontecia nos inferninhos, cabarés, opiários, gafieiras, clubes e bares da área da Lapa e por inúmeras casas ao longo da área portuária e da Praça Onze. Este lazer era povoado por trabalhadores autônomos, pequenos empresários, visitantes solteiros, jovens empreendedores e toda sorte de músicos, bailarinas, imigrantes pobres, malandros e contraventores. Ainda assim, a mística de tal organização espacial da vida noturna é bem mais marcada pelo olhar contemporâneo do que real. Não são poucos os relatos de encontros entre políticos, grandes empresários, proprietários de terras e membros das mais ricas famílias da república em estalagens mal afamadas das áreas da Lapa e do porto (LUSTOSA, 2001).

Ainda que a vida noturna tenha se expandido espacialmente e se ampliado socialmente, as suas duas formas de exibição se mantinham majoritariamente privadas. Os espaços públicos pareciam ser ocupados somente durante o período de espera antes ou após um espetáculo, um baile ou arranjo de dança. O lazer se mantinha privado também em muitos clubes e grêmios recreativos que ofereciam "bailes familiares" para "quem a diretoria julgasse conveniente" (Jornal do Brasil, 9 de maio de 1908, p. 12).

Apesar das demonstrações de práticas noturnas em toda a área central, a noite que ficou mais conhecida na cidade foi a das bandas da Lapa, entre a Rua dos Arcos e a Rua Taylor. Os cabarés já na década de 1910 abriam as portas para uma nova forma de lazer descontraído, misturando cantorias, shows de humor, apresentações circenses e orquestras de músicos. Suas atividades não eram, no entanto, desvinculadas das atrações mais conservadoras, pois, ao contrário, complementavam as noites dos frequentadores de teatros e cinemas da cidade.

Pela meia noite, o grupo abandona o bar ou a casa de chá, encaminhando-se para os clubs de jogo, onde cada qual pretende conquistar "a sua franceza", mas em cujo cabaret continua a beber e sahe regularmente só, recolhendo-se à casa ao nascer do sol completamente borracho [...]. (Careta, 17 de abril de 1920, p. 33).

A proximidade física de alguns desses estabelecimentos teria permitido a criação de muitos circuitos noturnos e encontros que ligavam as áreas da Cinelândia, da Lapa e da Tiradentes, núcleos da vida noturna carioca de então.

A chegada dos anos 1930 apontou novas direções, tanto no que diz respeito aos lugares para a vida noturna quanto no que se refere às práticas de seus usuários. A regulamentação do jogo e a perseguição aos vadios no centro levou a vida noturna para os bairros da orla carioca, especialmente para Botafogo, Urca e Copacabana. A efervescência das casas da Lapa foi sendo ainda mais suprimida durante a Era Vargas (entre 1930 e 1945), sendo a área alvo de medidas de ordenamento e moralização da cidade (FEIJÓ e WAGNER, 2014). Os poucos bolsões de vida noturna passaram a se concentrar na zona portuária, especialmente pela permanência ali de bordéis e casas de show que ofertavam divertimento barato para marinheiros. Ainda no início da década de 1930, o Rio de 
Janeiro começa a ser descrito como uma cidade pacata durante a noite, pois pouco se ouvia, muito menos se via. Na calada da noite apenas alguns gatos pardos se aventuravam em salões, bares e prostíbulos que ainda resistiam nas margens do centro urbano. Em um editorial escrito em 1936, em O Globo, perguntava-se "Por que o Rio dorme tão cedo?", afirmando adiante que

Si não houvesse outros argumentos a demonstrar o inconveniente dessa lethargia em que vive o Rio depois das 22 horas, bastaria aquelle que nos recorda a tristeza que representa para os turistas uma cidade profusamente iluminada mas com seus habitantes todos dormindo [...]. (O Globo, Geral, p. 1, 17 de outubro de 1936)

O sono profundo que parecia tomar a cidade durante a noite não era, no entanto, um dado geral para toda a urbe carioca, visto que os cassinos operavam a pleno vapor na época. Porém, nos limites aqui demarcados, não se tem notícia de qualquer papel significativo dos cassinos na promoção de uma vida noturna nos espaços públicos. Os cassinos absorveram, em parte, o público de elite carioca, que ainda ia aos teatros e cinemas no centro da cidade, mas que aos poucos procurava na orla do Rio novas formas de diversão (LESSA, 2005). Aos pobres e trabalhadores que viviam no centro a Lapa ainda permaneceu como lugar de vida noturna, ainda que impregnada de estigmas. Os terreiros, quintais e clubes proletários mantinham a vida divertida nos centros de bairros suburbanos, articulados com outras práticas noturnas, como ir aos restaurantes, cinemas e teatros que agora poderiam ser encontrados nas proximidades das estações de trem mais povoadas.

Os problemas com a vida pública se desdobraram também no uso dos espaços públicos e no desenrolar da vida social noturna. A remoção de parte do bairro da Lapa ainda no Estado Novo, a repressão policial à vadiagem e o estímulo ao jogo de azar foram algumas das medidas que aos poucos modificaram a vida noturna da cidade. Assim, o centro é aos poucos abandonado ao uso administrativo e o lazer da elite carioca passa, paulatinamente, para a orla da cidade, especialmente no bairro de Copacabana.

A Lapa, conhecida como lugar da boemia carioca entre os anos 1920 e 1930, aparece, a partir da década de 1940, como um palco vazio, sem brilho e sem os personagens celebrados das décadas anteriores. Esta área que parecia concentrar quase todo imaginário relacionado à vida noturna na cidade se viu paulatinamente deslocada de seu ponto no centro da vida boêmia carioca. A ideia de decadência é recorrente quando se refere à Lapa dos anos 1950 e demonstra o caráter moral e estigmatizado da pobreza, associada aqui à ideia de "vazio". Parece-nos, no entanto, exagerado o argumento de sua decadência repousar somente nos estudos sobre a localidade, ignorando o contexto em que esse processo se desenvolve. A decadência da Lapa parece ser um sintoma mais geral de esvaziamento da vida noturna de toda a cidade, durante o período. Em 1938, considerado um período áureo da boêmia carioca (DAMATA, 1978), havia ainda reclamações sobre uma vida noturna quase ausente na cidade, como na reportagem de O Globo sobre "O pyjama na história da cidade" (O Globo, 21 de maio de 1938) e as medidas do governo de Getúlio Vargas tinham atingido toda a capital, criando uma moralidade espacialmente abrangente e temporalmente recortada no período noturno. 
"Na Calada da Noite": Modernidade e Conservadorismo na Vida Noturna Carioca (1760-1950)

\section{Conclusões}

Das movimentadas noites dos cabarés da Lapa às concorridas peças dos teatros do Largo do Rocio sobraram poucas evidências e alguns topônimos importantes. Há uma nítida articulação entre as atividades realizadas e o desenvolvimento de ações sobre o espaço público da cidade, como a adoção de melhorias no sistema de iluminação pública, nos sistemas de transportes, na urbanização de ruas e praças, na regulação dos comportamentos etc. A partir de tais articulações podemos concluir que há três grandes dimensões associadas à vida noturna na cidade do Rio de Janeiro: a primeira é aquela que trata da introdução da vigilância técnica através da iluminação dos espaços públicos; a segunda diz respeito às práticas e aos comportamentos sociais; e, por fim, a terceira está relacionada aos lugares que tiveram maior visibilidade durante o período noturno na cidade. Cada dimensão demonstrou possuir pontos problemáticos a serem discutidos, repercutindo, assim, o momento em que mudanças em cada uma delas afetaram as outras.

O primeiro ponto diz respeito ao desenvolvimento de tecnologias para iluminar a cidade. A escuridão dos espaços públicos durante a noite é um tema recorrente nas manchetes de jornais e há relatos ainda anteriores aos séculos XX e XIX que abordam o problema. A iniciativa de se iluminar as ruas durante as noites possui a princípio uma relação com o policiamento e a contenção dos crimes durante o período. Até meados do século XIX esta relação prevalecia sobre as demais, estando a iluminação a cargo dos membros do corpo policial. As mudanças nas razões de se iluminar e no imperativo empresarial ligado à produção de energia contribuíram para que esta atribuição passasse a ser compartilhada entre o setor público e o empresariado nacional e internacional. De fato, a iluminação pública transformada em negócio deixa de estar ligada somente ao controle dos públicos e se transforma em um instrumento para o processo mais geral de modernização urbana, associado, é claro, às reformas urbanas ocorridas a partir da metade do século XIX.

O segundo ponto está ligado ao aparato repressivo que a capitalidade impunha sobre os corpos e os comportamentos dos sujeitos nos espaços públicos. A repressão de alguns comportamentos era uma reconhecida marca do período escravocrata e tinha um profundo caráter social e racial. As notícias das páginas policiais denunciavam as ações ilegais de pessoas, geralmente "mulatas e pretas", presas por vadiagem, por roubo, pela prática da capoeira ou simplesmente por vagarem à noite pelas ruas. O controle dos comportamentos tinha como prerrogativa permitir que práticas mais valorizadas, como as idas ao teatro, à ópera e aos restaurantes ocorressem com menores percalços, sejam eles imaginados ou reais. Talvez em razão disto, até a metade do século XIX, existissem poucas referências de saídas à noite e atividades nos espaços públicos. Em geral, os lugares de sociabilidade mantinham-se restritos às residências e o medo de sair em ruas vazias e praticamente escuras tinha precedência nas decisões individuais.

Um terceiro elemento de discussão pode ser encontrado na localização da vida noturna na cidade e sua relação com a visibilidade dada pelas fontes oficiais para algumas formas de lazer noturno. Neste caso há uma grande relação entre o consumo da noite pelos setores médios da população urbana, os quais ocupavam majoritariamente as plateias 
das óperas, dos teatros e dos salões de dança. Os cariocas pareciam adorar as suas ruas, parques e praças, mas evitavam fazer uso de seus equipamentos durante a noite. A vida noturna, quando existia, parecia se restringir aos centros da vida urbana, como a Praça Tiradentes (antigo Rocio), a região da Cinelândia e as bordas do centro administrativo, no atual bairro da Lapa. As referências encontradas sobre atividades fora do circuito da área central são poucas e apresentam uma maior identidade com ambientes privados, como clubes, agremiações esportivas, cordões de carnaval, casas de dança etc. Pouca vida noturna parece ter animado os espaços públicos, mesmo na Lapa, onde opiários, cabarés, botequins e gafieiras mantinham um constante fluxo de pessoas durante o período noturno.

Um quadro geral deste artigo apresentaria muitas geografias da vida noturna, ainda que delimitadas pelas demarcações das fontes da pesquisa, desequilibradas pelo caráter moralizante da sociedade carioca de então. Ainda assim, há uma nítida geografia da vida noturna, demarcada pela vida pública da cidade, limitada até o início do século XX pela área central do Rio de Janeiro. Há também uma geografia dos circuitos noturnos, passível de ser descrita com a introdução do bonde a partir da segunda metade do século XIX, articulando os bairros residenciais aos largos e praças do antigo centro. Essas geografias poderiam ainda ser pensadas em relação a uma geografia da luminosidade, na qual velas, candeeiros, bicos de gás e luminárias elétricas demarcaram desde o final do século XVIII os limites da ordem pública e até mesmo da cidade. Por fim, uma geografia da sociabilidade noturna no período republicano que, para além das histórias da Lapa, do Largo do Rocio e da Cinelândia, possui uma muito pouca conhecida vida noturna nas cercanias das gafieiras, escolas de samba, clubes e cassinos. Histórias que se encontravam na calada da noite, sem lâmpadas para lhes oferecer visibilidade ou eventos para enaltecer nas páginas de jornal. Outras geografias ainda podem ser pensadas. Há muitos capítulos a serem escritos sobre as noites cariocas.

\section{Referências Bibliográficas}

ABREU, M. A. A evolução urbana do Rio de Janeiro. Rio de Janeiro: Instituto Pereira Passos, 2006.

BALDWIN, P. In the Watches of the Night: Life in the Nocturnal City, 1820-1930. Chicago and London: The University of Chicago Press, 2012.

BUREAU, L. Géographie de la nuit. Montreal: L’Hexagone, 1997.

CAVALCANTI, N. O Rio de Janeiro setecentista: a vida e a construção da cidade da invasão francesa até a chegada da corte. Rio de Janeiro: Jorge Zahar Editor, 2004.

DAMATA, G. Antologia da Lapa: vida boêmia no Rio de ontem. Rio de Janeiro: Codecri, 1978.

DUNLOP, C. J. Subsídios para a história do Rio de Janeiro. Rio de Janeiro: Imperial Novo Milênio, 2008. 
"Na Calada da Noite": Modernidade e Conservadorismo na Vida Noturna Carioca (1760-1950)

FEIJÓ, L.; WAGNER, M. Rio cultura da noite. Rio de Janeiro: Casa da Palavra, 2014.

FERREIRA, M. M. A evolução da iluminação na cidade do Rio de Janeiro: contribuições tecnológicas. Rio de Janeiro: Synergia/Light, 2009.

GONÇALVES, R. Sá. Os ranchos pedem passagem: o carnaval no Rio de Janeiro do começo do século XX. Rio de Janeiro: Secretaria Municipal de Cultura, 2007.

LESSA, C. O Rio de todos os Brasis. Rio de Janeiro: Record, 2005.

LIMA, E. F. W. Arquitetura do espetáculo: teatros e cinemas na formação da Praça Tiradentes e da Cinelândia. Rio de Janeiro: Editora da UFRJ, 2000.

LUSTOSA, I. Lapa do Desterro e do desvario: uma antologia. Rio de Janeiro: Casa da Palavra, 2001.

MATTOS, M. B. Vadios, jogadores, mendigos e bêbados na cidade do Rio de Janeiro do início do século. 1991. Dissertação (Mestrado em História Social) - Universidade Federal Fluminense. Niterói: UFF, 1991.

MATTOS, R. B. A dinâmica dos espaços de prostituição na cidade do Rio de Janeiro: 1840-1940. In: RIBEIRO, Miguel Angelo; OLIVEIRA, Rafael da Silva. Território, sexo e prazer: olhares sobre o fenômeno da prostituição na geografia brasileira. Rio de Janeiro: Gramma, 2011.

MELBIN, M. Night as Frontier. American Sociological Review, v. 43, n. 1, p. 3-22, 1978. . Night as Frontier: Colonizing the World after Dark. New York: The Free Press, 1987.

MENDONÇA, L. L. Reflexos da cidade: a iluminação pública do Rio de Janeiro. Rio de Janeiro: Centro da Memória da Eletricidade no Brasil, 2004.

MITIDIERI, J. Contos e contos: histórias, estórias e lendas do Rio de Janeiro. Rio de Janeiro: [s.n.], 2008.

MOURA, R. Tia Ciata e a pequena África no Rio de Janeiro. Rio de Janeiro: Secretaria Municipal de Cultura, Divisão de Editoração, 1995.

MUMFORD, L. A cidade na história: suas origens, transformações e perspectivas. São Paulo: Martins Fontes, 1998.

NASAW, D. Going Out: the Rise and Fall of Public Amusements. Cambridge: Harvard University Press, 1993. 
Marcos Paulo Ferreira de Góis

NORTON, W. Historical Analysis in Geography. London: Longman, 1984.

PALMER, B. Cultures of Darkness: Night Travels in the Histories of Transgression. New York: Monthly Review Press, 2000.

PESAVENTO, F. O colonial tardio e a economia do Rio de Janeiro na segunda metade dos setecentos: 1750-90. Estudos Econômicos, São Paulo, v. 42, n. 3, p. 581-614, 2012.

SCHIVELBUSCH, W. The Policing of Street Lighting. Yale French Studies, n. 73, p. 61-74, 1987.

SEGAWA, H. Ao amor do público: jardins no Brasil. São Paulo: Nobel/Fapesp, 1996.

WILLIAMS, R. Night Spaces: darkness, deterritorialization and social control. Space and Culture, v. 11, n. 4, p. 514-532, 2008.

Recebido em: 20/11/2015 Aceito em: 29/12/2015 